\title{
Tendências do consumidor em turismo: a oferta no Paraná (Brasil) para demandantes de experiências
}

\section{Tendencias del consumidor en turismo: la oferta en Paraná (Brasil) para demandantes de experiencias}

\section{Consumer trends in tourism: the offer in Paraná (Brazil) for experiences seekers}

Marina Lima Santos, Universidade Federal do Paraná, Brasil. slimamarina@gmail.com Débora Gonçalves Alencar, Universidade Federal de Ouro Preto (UFOP), Brasil. deborag.alencar@gmail.com Adriely Andrade e Souza, Universidade Federal do Paraná, Brasil. dryhandrad@hotmail.com José Manoel Gonçalves Gândara, Universidade Federal do Paraná, Brasil. imggandara@yahoo.com.br

\section{RESUMO}

O turismo, como atividade econômica, está em constante busca de aperfeiçoar a forma como seus produtos e serviços são produzidos e entregues ao consumidor, este por sua vez encontra - se a cada dia mais envolvido em adquirir experiências em suas viagens. Surge desta forma, o direcionamento do marketing sob as premissas da economia da experiência. Visto isso, este trabalho tem como objetivo diagnosticar os atrativos que compõem a dimensão de evasão de Pine e Gilmore (1999) no estado do Paraná, Brasil. Para tanto, é realizado uma pesquisa bibliográfica exploratória, com o aporte teórico-metodológico do Plano Paraná Turístico 2026 - pacto para um destino inteligente - seguido de um levantamento de dados quantitativos e qualitativos do potencial do turismo no estado do Paraná. Conclui - se que a conformação de produtos experienciais está consolidada com aporte da segmentação da demanda, interligada com perfis de consumidores e com apoio dos conceitos da economia da experiência.

Palavra chave: Turismo de experiência, Evasão, Personas, Paraná Turístico 2026.

\section{RESUMEN}

El turismo, como actividad económica, está en constante búsqueda de perfeccionar la forma como sus productos y servicios son producidos y entregados al consumidor, éste a su vez se encuentra cada día más involucrado en adquirir experiencias en sus viajes. Surge de esta forma, el direccionamiento del marketing bajo las premisas de la economía de la experiencia. En este sentido, este trabajo tiene como objetivo diagnosticar los atractivos que componen la dimensión de evasión de Pine y Gilmore (1999) en el estado de Paraná, Brasil. Para ello, se realiza una investigación 
bibliográfica exploratoria, con el aporte teórico-metodológico del Plan Paraná Turístico 2026 - pacto para un destino inteligente - seguido de un levantamiento de datos cuantitativos y cualitativos del potencial del turismo en el estado de Paraná. Se concluye que la conformación de productos experienciales está consolidada con aporte de la segmentación de la demanda, interconectada con perfiles de consumidores y con apoyo de los conceptos de la economía de la experiencia.

Palabra clave: turismo de experiencia, Evasión, Personas, Paraná Turístico 2026.

\section{ABSTRACT}

Tourism as an economic activity is constantly seeking to optimize the way its products and services are produced and delivered to the consumers, who, in turn, find themselves increasingly involved in acquiring experiences in their travels. Consequently, the steering of marketing under the premises of experience economy has arisen. This study seeks to diagnose the attractions that make up the escapism dimension of Pine and Gilmore (1999) in the state of Paraná. To do this, an exploratory bibliographic research has been carried out with the theoretical-methodological contribution of the Paraná Plan 2026 - Agreement for an intelligent destination - followed by a survey of quantitative and qualitative data on tourism potential in the state of Paraná. Based on the observations, it may be concluded that the conformation of experiential products is consolidated with the contribution of demand segmentation interconnected with consumer profiles and the support of the concepts of experience economy.

Keywords: Experience Tourism, Escapism, People, Paraná Turístico 2026.

\section{INTRODUÇÃO}

O turismo é um agente de produção e transformação dos lugares no qual atua. Ao longo das últimas décadas tem apresentado alterações no processo de consumo, em consequência de um mercado com consumidores mais conscientes, caracterizado por grupos de pessoas diferentes do chamado turismo de massa, são compradores potenciais da atividade do turismo uma vez que se propõem a um maior envolvimento com o destino (Middleton e Clarke, 2002, Ejarque 2005, Petrocchi, 2001).

Desta forma, empregam-se estudos, planos e estratégias para potencializar recursos, minimizar aspectos negativos e maximizar relações positivas, a fim de gerir uma relação oferta e demanda que atenda à qualidade, diversidade, reputação e lealdade da atividade do turismo mediante a proposta de gerir experiências (Middleton e Clarke, 2002).

Para Buhalis (2000), o marketing de destinos tem por principal objetivo coordenar as partes envolvidas com o turismo para gerar experiências positivas aos turistas. Embora o marketing tradicional trate da comercialização de destinos, na atualidade também se trata do marketing experiencial, na qual é colocada em questão a noção de valor (além do sentido monetário) do produto ou serviço adquirido (Pine e Gilmore, 1999).

Visto este panorama, o trabalho vigente utiliza o plano Paraná Turístico 2026 - Pacto para um destino inteligente - como norteador da conformação de produtos para os novos consumidores do turismo no estado do Paraná/Brasil. O referido documento trata-se de um masterplan criado a partir da união do CEPATUR - Conselho Paranaense de Turismo, do Grupo 
de Estudos Pró-Planejamento Decenal do Turismo do Paraná e coordenado por uma Comissão Técnica responsável para definir metodologias e ações para elaboração de um plano que obtivesse um direcionamento estratégico para a execução da atividade do turismo (Paraná, 2016).

O Plano aborda o desenvolvimento do turismo mediante a contextualização de três eixos estratégicos: marketing e inovação, qualidade e competitividade, governança e sustentabilidade, esboçando um diagnóstico da situação atual da atividade turística, enfoques e tendências, o que permite embasar definições estratégicas para conformação de produtos.

O eixo Governança e Sustentabilidade visam o planejamento integrado com a finalidade de gerir o turismo promovendo o desenvolvimento econômico e social, valorização cultural, qualidade de vida da população e conservação do meio ambiente a partir do uso equilibrado dos recursos existentes. $O$ eixo Qualidade e Competitividade têm como enfoque ampliar, qualificar e dinamizar a oferta turística para atingir vantagem competitiva em diferentes mercados. O eixo referente ao Marketing e Inovação tem como intuito fomentar e promover o estado do Paraná através da comercialização do potencial turístico existente nos destinos (Paraná, 2016).

Dentre os enfoques e desafios apresentados no eixo de marketing e inovação do plano Paraná Turístico 2026, encontram-se o foco em segmentos, mercados prioritários e desenvolvimento de roteiros integrados, no qual a inovação de produtos experienciais e a busca de novos mercados são premissas desafiadoras do marketing de destinos turísticos.

A problemática que se forma, com as atuais modificações de consumo, quanto às configurações de mercado no turismo consistem em como produzir experiências dentro do desenvolvimento de novas ofertas. Segundo Gelder (2010) integrar serviços e produtos às teorias da economia da experiência se configuram o principal desafio enfrentado pelas empresas turísticas.

Mediante a este fato, a aplicabilidade da economia da experiência gerenciada a partir das dimensões propostas por Pine e Gilmore (1999), sendo Educação/Aprendizagem, Evasão, Entretenimento, Estética/Contemplação, podem auxiliar no conhecimento relacionado à oferta e demanda para o turismo.

Sob este viés, o objetivo do presente trabalho é diagnosticar os principais atrativos que se relacionam com a dimensão evasão ofertados no estado do Paraná, e responder a seguinte pergunta: "No estado do Paraná a oferta de atrativos turísticos para buscadores de experiências de evasão está consolidada?".

Para tanto, são utilizados estudos de perfis de demandas trazidos pelo Plano Paraná Turístico 2026, a partir de um recorte específico sendo este a dimensão de evasão, para compreender o novo comportamento do consumidor, bem como as concepções conceituais que permeiam a economia da experiência. Uma vez em que a premissa central da economia da experiência é o valor acrescentado através de novos aspectos de produtos e serviços (Mehmetoglu e Engen 2011, GELTER 2010, Anderson, 2015).

Este artigo está dividido em três partes, sendo a primeira o esboço sobre a economia da experiência e suas dimensões e concepções, seguido da metodologia de pesquisa adotada, análise dos resultados e implicações referente à dimensão experiencial de evasão de Pine e Gilmore (1999) para o estado do Paraná e considerações finais. 


\section{A ATUAÇÃO DA ECONOMIA DA EXPERIÊNCIA NA ATIVIDADE DO TURISMO - NOVOS CONSUMIDORES, NOVOS PARADIGMAS}

O destino turístico pelo viés do marketing pode ser visto como o produto em si, dotado de serviços básicos para o acontecimento de atividades de lazer e preparado para atender um mercado competitivo (Barrado, 2004). Em um sentido mais sociológico, o destino também é visto como lugar de encontro, de chegada dos turistas e para a vivência de experiências sociais (Framke, 2010; Flores e Mendes, 2014). Entretanto, de forma mais atual, Jovicic (2017) trata do conceito de destino inteligente como um sistema que considera o todo do destino e, além disso, considera a tecnologia como colaboradora na relação entre empresas de turismo e turistas.

Apesar de diferentes perspectivas na conceituação de destino turístico, há um consenso sobre o papel do turista como eixo central, sem o qual a atividade não acontece (Framke, 2010). Mediante a essa constatação, o bom desenvolvimento de um destino se relaciona com o conhecimento sobre a demanda que por sua vez apresenta especificidades.

O conhecimento relacionado à demanda resulta na segmentação do mercado turístico, sendo um facilitador na identificação e satisfação das necessidades do turista (Middleton e Clarke, 2002). Contudo, na atualidade, estudos demonstram que a forma de segmentação orientada pela oferta precisa ser revisada e orientada pela demanda, já que os turistas são exigentes no momento da compra por serviço ou produto turístico, ou seja, além do ato de adquirir algo buscam por um sentido maior (Neuhofer; Buhalis e Ladkin, 2012).

As tecnologias de informação e comunicação favorecem a expansão dos perfis de demanda pelos chamados "novos consumidores", e assim a necessidade de estratégias de marketing tanto on quanto off-line para agregar valor ao produto turístico, colocando-os ao alcance de todos os possíveis consumidores (Anderson, 2015, Middleton e Clarke, 2002).

Com relação aos novos consumidores, foi traçado dez perfis de turistas (observados no quadro 1) no estudo "The Future Travelers Tribes - compreendendo o turista de amanhã" em 2015, realizado pela Future Fundation para o Observatório de Tendências de Viagens da AMADEUS, indicando tendência de comportamento e consumo desses turistas, onde apenas um pode representar o que os autores chamam de "tribo" (The Future Travelers Tribes, 2015).

Quadro 1. Perfis de turistas - Amadeus

\begin{tabular}{|c|c|}
\hline Perfil & Característica \\
\hline \multicolumn{2}{|c|}{ Prevista em 2007 para 2020} \\
\hline Idosos ativos & $\begin{array}{l}\text { Aposentados com saúde, tempo e renda para } \\
\text { desfrutar da vida. }\end{array}$ \\
\hline Clãs globais & Viajam para visitar parentes e amigos. \\
\hline Cosmopolitas & $\begin{array}{l}\text { Residências e trabalhos em locais diferentes, logo } \\
\text { viagens com frequência. }\end{array}$ \\
\hline Executivos globais & Viajam para o exterior à trabalho. \\
\hline
\end{tabular}




\begin{tabular}{|l|l|}
\hline \multicolumn{2}{|c|}{ Prevista em $\mathbf{2 0 1 5}$ para $\mathbf{2 0 3 0}$} \\
\hline Buscadores de facilidades & $\begin{array}{l}\text { Valorizam as facilidades em viajar oferecidas } \\
\text { por alguém, sem precisar planejá-las ou buscar } \\
\text { informações sobre o destino. }\end{array}$ \\
\hline Puristas culturais & Aproveitam a viagem para sair da rotina do cotidiano. \\
\hline Buscadores de reconhecimento & $\begin{array}{l}\text { Relacionam a viagem com oportunidades de melhorar } \\
\text { sua reputação. }\end{array}$ \\
\hline Caçadores de recompensa & Aproveitam a viagem para bem-estar mental e físico. \\
\hline Viajantes por obrigação & $\begin{array}{l}\text { As viagens são limitadas por questões profissionais } \\
\text { e alguns deles aproveitam essas oportunidades para } \\
\text { interesses pessoais. }\end{array}$ \\
\hline Viajantes éticos & $\begin{array}{l}\text { Viajam de forma consciente, buscando respeitar } \\
\text { questões ambientais, culturais, econômicas e } \\
\text { políticas. }\end{array}$ \\
\hline
\end{tabular}

Fonte: Elaborado pelas autoras, baseado em The Future Travelers Tribes - compreendendo o turista de amanhã (2015) e em Thomaz (2015).

De forma semelhante, o Plano Paraná Turístico 2026 elencam dez tendências-chaves para a próxima década. Nessas tendências há predominância do uso de novas tecnologias de informação e comunicação, crescimento da economia colaborativa, aumento do conhecimento referente à demanda e seu monitoramento, além da concepção dos destinos turísticos inteligentes como oportunidade de gestão (Paraná, 2016). Esses eixos trabalhados pelo marketing levam em consideração as tendências da demanda, reafirmando a necessidade de atualizar roteiros com foco na segmentação da mesma e suas tendências, voltadas às experiências (Buhalis, 2016).

\subsection{Da experiência às personas}

O turismo, enquanto atividade econômica, está em constante busca de otimização na forma como seus produtos e serviços são produzidos e entregues ao consumidor. Por isso, alguns conceitos trabalhados por Pine e Gilmore (1999) sobre a economia da experiência e essa transição de economias podem ser utilizados pelo turismo, os autores trabalham a perspectiva das experiências memoráveis, baseadas na co-criação ${ }^{1}$ de experiências envolventes (Prahalad e Ramaswamy, 2003).

$\mathrm{Na}$ economia da experiência o atributo chave é a personalização do produto ou serviço, ou seja, a apresentação de algo único que atende as especificidades de cada convidado (cliente) com o intuito de provocar sensações e emoções. Vale ressaltar que no âmbito da experiência não se espera seja memorável para todos, visto que o sentido da experiência é pessoal e

1. O conceito de co-criação está relacionado ao fato de os envolvidos no evento da experlência criarem juntos o valor de determinada experiência. Binkhorst (2006) associa co-criação como uma característica na experiência turística do proksumer, considerado um dos "novos consumidores" que vive a era das tecnologias e sempre está conectado via redes sociais, ou seja, procura e compartilha suas experiências de consumo (BINKHORST, 2006). 
dependente de níveis emocionais, físicos, intelectuais ou espirituais do indivíduo (Mondo e Gândara, 2017).

A chave, portanto, é compreender que experiências são condicionadas aos fatores internos de percepção e valor do indivíduo do que aos fatores externos, os produtos e serviços em si. No que tange às características da experiência proposta por Pine e Gilmore (1999), duas dimensões são apontadas e dentro delas quatro "categorias". A figura 1 demonstra como esses aspectos da teoria sobre a economia da experiência se organizam ao todo.

Figura 1. Dimensões da economia da experiência baseadas em Pine e Gilmore (1999)

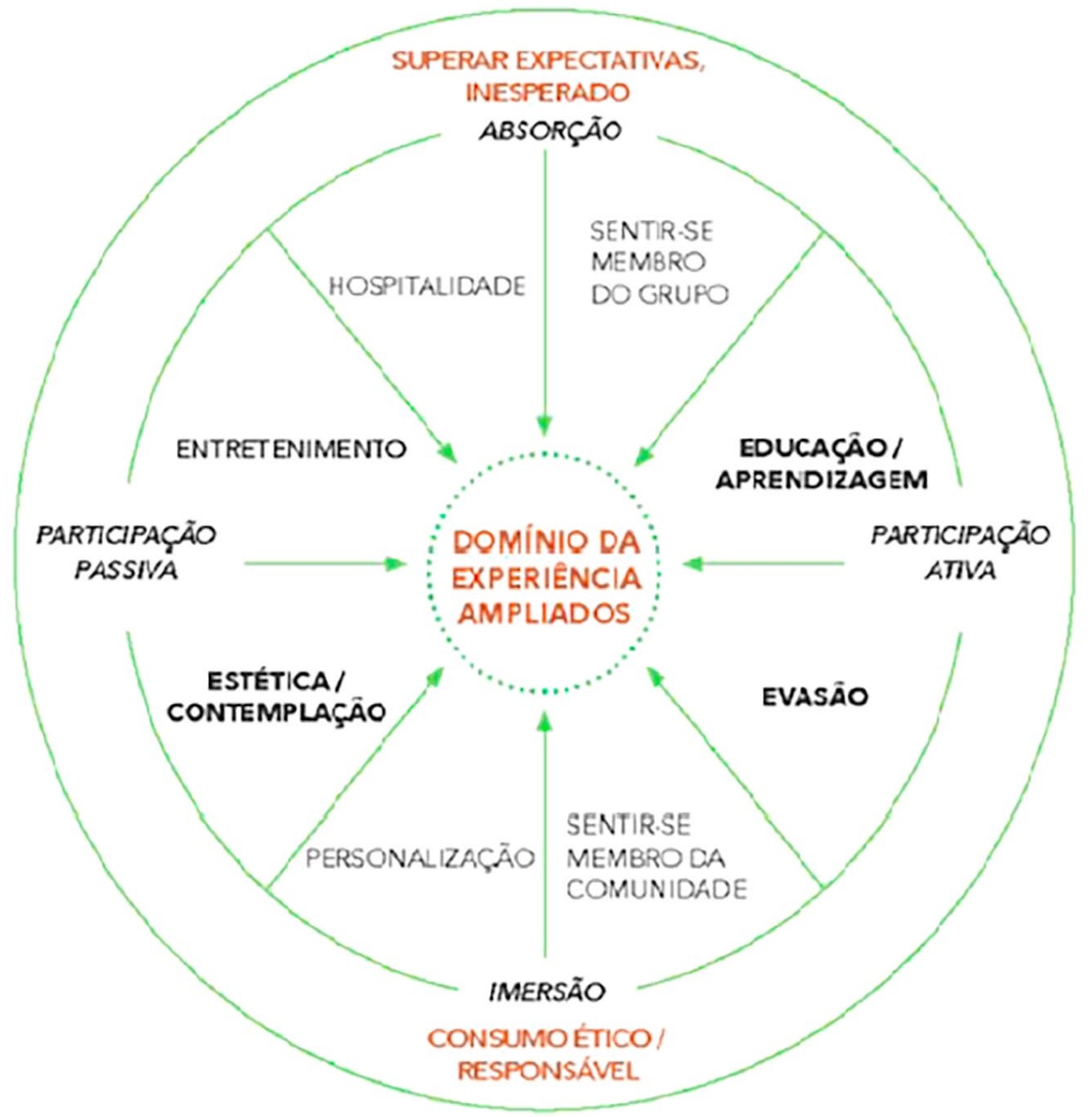

Fonte: Plano Paraná Turístico 2026 - Pacto para um destino inteligente (2016)

No eixo horizontal é possível perceber que a participação dos clientes possui dois extremos identificados como participação passiva e participação ativa, na passiva, a cliente não afeta diretamente no evento, pois o mesmo se atém a observar e ouvir o que está ocorrendo. Por outro lado, no extremo da participação ativa, o cliente tem papel fundamental na criação da experiência, influenciando completamente no evento onde o próprio indivíduo 
cria a experiência. Quanto ao eixo vertical, o extremo referente à absorção, ocorre pelo fato de o consumidor vivenciar a experiência de fora, não participa ativamente, porém assimila-a, sente-se mentalmente inserido na mesma. No último extremo está a imersão, onde o cliente se entrega inteiramente ao evento, participa durante a execução e envolve-se a ponto de sentir-se parte da experiência.

Observa-se que na figura 1, as características da participação ativa têm mais relação com o turista, em como ele pode/deseja participar do evento da experiência, e já a participação passiva se relaciona em como os membros da comunidade ou conformadores de produtos podem/desejam atuar no evento da experiência do turista em questão. A dimensão de imersão trabalha as questões de responsabilidade do turista para com o destino ou produto consumido e a dimensão de absorção traz a questão do inesperado, da surpresa e expectativas do turista (Thomaz, 2016).

Para Pine e Gilmore (1999), os turistas consomem histórias e experiências relativas aos seus interesses e necessidades pessoais que podem ser encaixadas em quatro dimensões: Entretenimento, aprendizagem/educação, evasão e estética. Para cumprir o objetivo deste artigo, a categoria evasão será evidenciada. Com o aporte conceitual das características apresentada e na figura 1, as experiências classificadas como de evasão possuem participação ativa e com a imersão nas atividades turísticas.

- Entretenimento: requer a atenção dos participantes com prontidão, são experiências onde o indivíduo participa de maneira passiva no evento e o seu envolvimento com o mesmo é de absorção.

- Educacional: são experiências obtidas por absorção, onde os indivíduos têm uma participação mais ativa, as experiências educacionais envolvem-se ativamente na imaginação do consumidor e intriga-os a aprender algo novo. O conhecimento de experiências anteriores interfere na apreciação por parte do consumidor.

- Evasão: são o tipo de experiências onde os clientes participam ativamente e são totalmente envolventes (imersão) no evento. Estas experiências podem ter uma vertente educacional ou de entretenimento, seja qual for os consumidores têm um maior envolvimento de imersão.

- Estética: experiências que permitem somente uma participação reduzida do participante (passiva), porém, este encontra-se imerso e totalmente envolvido no ambiente.

O Plano Paraná Turístico 2026 elaborou dez perfis de turistas para o estado do Paraná - BR (figura 2) com base em dados de demanda turística do Brasil e de alguns municípios do Paraná somados com a técnica de "personas" do "design thinking". De acordo com Horodyski (2014), as personas são construídas por meio do design que propõe a criação de produtos distintos para características de diferentes consumidores, e desta forma origina possíveis perfis de consumo. 
Figura 2. Perfis da demanda turística

\begin{tabular}{|c|c|c|c|}
\hline GRUPOS & \multicolumn{1}{|c}{ PERSONAS } \\
\hline EVASÃO & BUSCADORES DE EXPERIÊNCIAS DE CULTURA \\
& BUSCADORES DE EXPERIÊNCIAS DE NATUREZA \\
\hline $\begin{array}{c}\text { APRENDIZAGEM/ } \\
\text { EDUCAÇÃO }\end{array}$ & BUSCADORES DE EXPERIÊNCIAS DE NEGÓCIOS \\
\hline $\begin{array}{c}\text { BUSCADORES DE EXPERIÊNCIAS DE MEIO URBANO } \\
\text { ENTRETENIMENTO }\end{array}$ & BUSCADORES DE EXPERIÊNCIAS DE SAÚDE \\
\hline $\begin{array}{c}\text { ESTÉTICA/ } \\
\text { CONTEMPLAÇO }\end{array}$ & BUSCADORES DE EXPERIÊNCIAS DE MEIO RURAL \\
\hline BUSCADORES DE EXPERIÊNCIAS DE FÉ
\end{tabular}

Fonte: Paraná Turistíco 2026 - Plano Estratégico de Marketing para um destino inteligente (2016).

A dimensão de evasão, da qual o artigo possui enfoque, tem como perfil de demanda as personas de Cultura e Natureza, como apresentada na figura 2. As características de consumo foram desenhadas no Plano Paraná Turístico 2026 - Plano Estratégico de Marketing para um Destino Inteligente (2018), funcionando como norteadora para a conformação de produtos turísticos que atendam as duas personas em questão, observados nas figuras 3 e 4. 
Figura 3. Características da persona buscadora de experiências de cultura

\begin{tabular}{|c|c|}
\hline & $\begin{array}{l}\text { BUSCADORES DE EXPERIENCIAS DE CULTURA } \\
\text { As principais motivaçốes são Cultura, História, Gastronomia e Eventos }\end{array}$ \\
\hline & 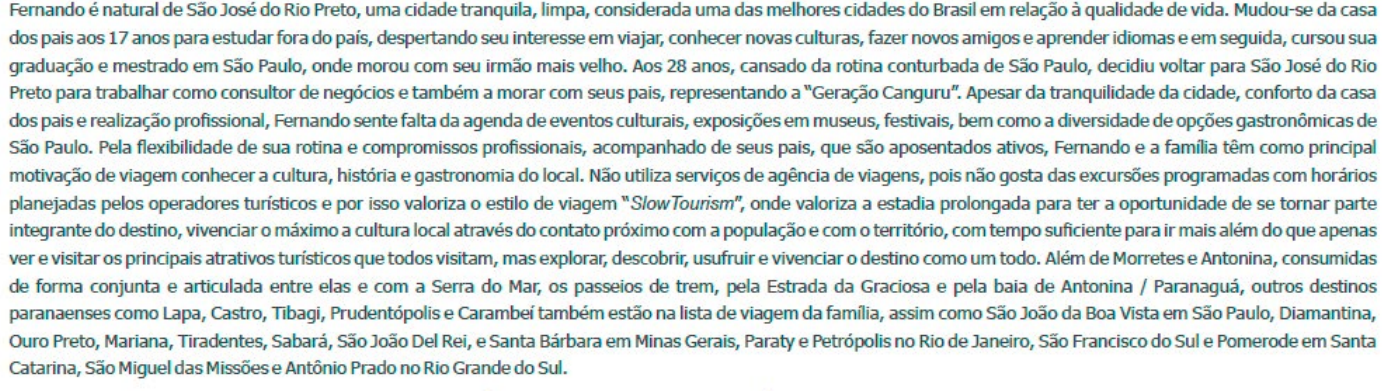 \\
\hline & EXPERIÊNCIA DE CONSUMO TURÍSTICO \\
\hline $\begin{array}{l}\text { PRÉ- } \\
\text { CONSUMO }\end{array}$ & $\begin{array}{l}\text { Fernando gosta de organizar a viagem de acordo com os interesses e necessidades da familia. De tão organizado, ao mesmo tempo em que pesquisa as informaçôes sobre o } \\
\text { destino na internet, Fernando elabora um guia personalizado de acordo com as informaçôes e dicas que encontra na internet através da leitura de matérias, dicas em blogs e } \\
\text { fóruns especificos de viajantes, opiniốes dos usuários no TripAdvisor, página oficial do destino na internet, no Facebook, Instagram e outras redes sociais. Aproveita a } \\
\text { facilidade de comunicação das redes sociais para se relacionar e conversar com os gestores de turismo responsáveis pela comunicação e promoção turistica online através da } \\
\text { funcionalidade de chat da página oficial do destino no Facebook. Sente-se valorizado quando suas perguntas e dúvidas são respondidas prontamente e motiva-se ainda mais } \\
\text { para buscar mais informaçốes turísticase conhecer o destino. Também busca uma experiência turística virtual no destino através de serviços e tecnologias de realidade virtual } \\
\text { e GPS como Google Maps, Google Street View e Google Earth, principalmente para organizar as atividades, atrativos turísticos e localização dos hotéis, restaurantes e outros } \\
\text { pontos de interesse. }\end{array}$ \\
\hline COMPRA & $\begin{array}{l}\text { Não utiliza serviços de agência de viagens e tem conhecimento e experiência para elaborar um roteiro autêntico e personalizado para a familia. Normalmente viajam de carro } \\
\text { para aproveitar o momento em familia, aproveitar a paisagem e ter liberdade e flexibilidade para fazer paradas e conhecer pontos de interesse, restaurantes e lanchonetes } \\
\text { locais, memoriais, igrejas, entre outros atrativos que nấo estavam planejados. Tem preferência por meios de hospedagem, econômicos, alternativos e que oferecem o maior } \\
\text { contato possivel com a cultura local como pequenos hotéis de cadeias locais e, principalmente Airbnb. }\end{array}$ \\
\hline $\begin{array}{l}\text { CONSUMO } \\
\text { CENTRAL }\end{array}$ & 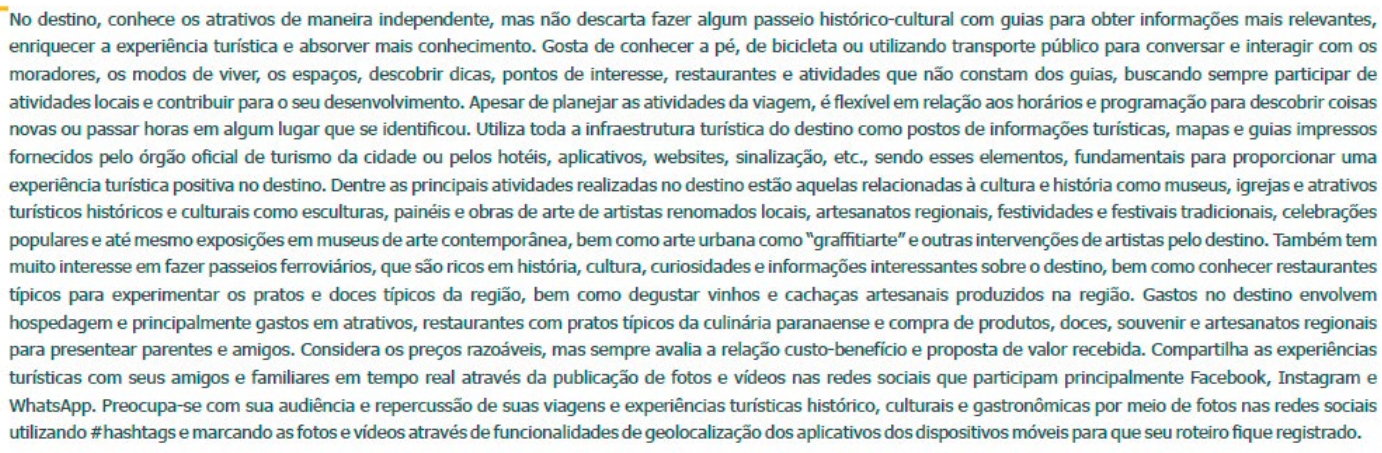 \\
\hline PÓS- & $\begin{array}{l}\text { Após a viagem, além de fazer comentários e avaliar os atrativos, restaurantes e meios de hospedagem, faz posts relevantes e informativos em seu blog de viagens sobre sua } \\
\text { experiência no destino com o objetivo de colaborar com a viagem de outros viajantes, aumentar sua audiência e número de seguidores, bem como tornar-se referência. }\end{array}$ \\
\hline
\end{tabular}

Fonte: Paraná Turistíco 2026 - Plano Estratégico de Marketing para um destino inteligente (2016). 
Figura 4. Características da persona buscadora de experiências de natureza

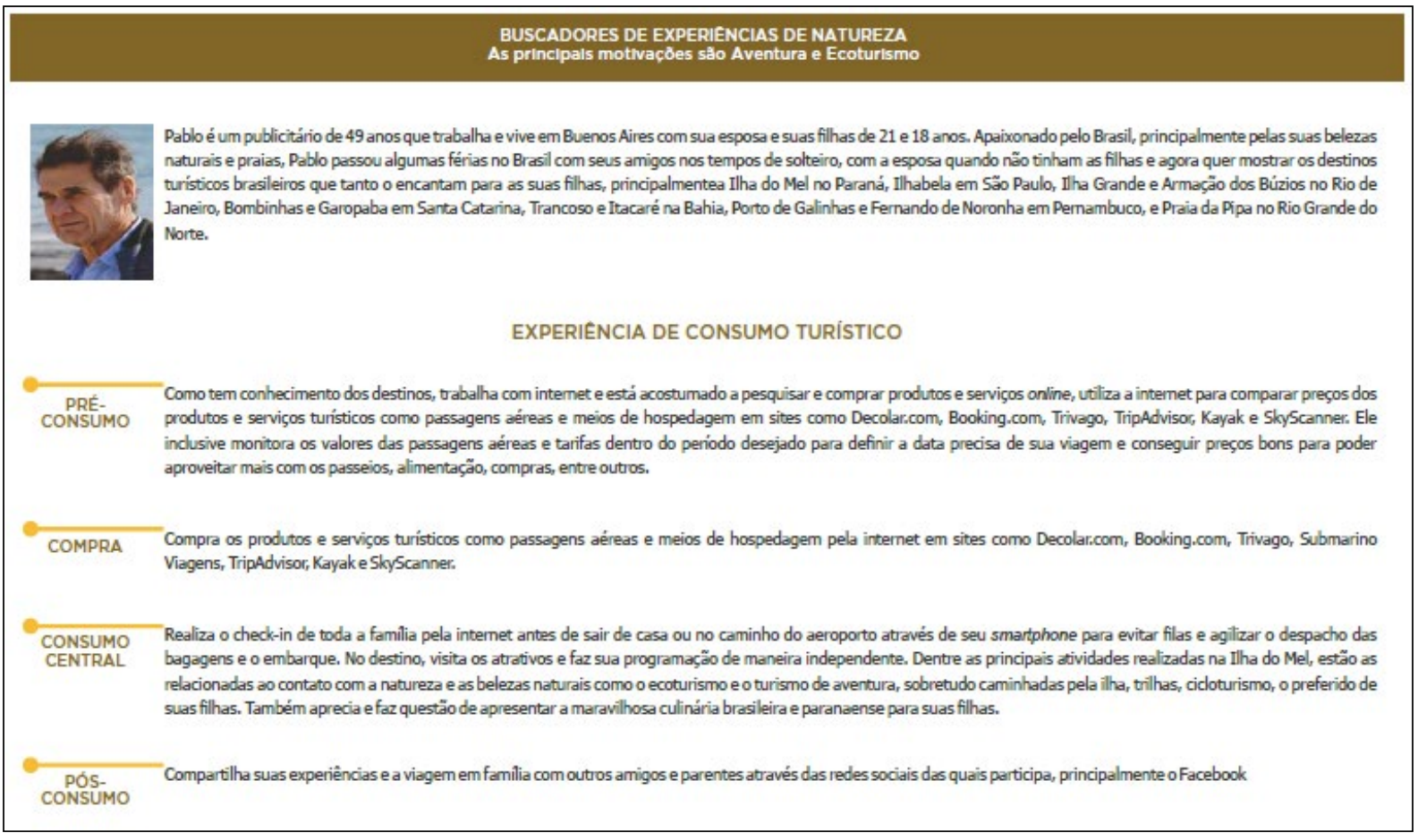

Fonte: Paraná Turistíco 2026 - Plano Estratégico de Marketing para um destino inteligente (2016).

De acordo com Thomaz (2016) e com o Plano Paraná turístico 2026 - Plano Estratégico de Marketing para um Destino Inteligente (2018), a dimensão de evasão é de essência ativa, ou seja, os conformadores de produtos devem fazer com que os turistas fiquem imersos na experiência.

\section{DELINEAMENTO METODOLÓGICO DA PESQUISA.}

Visando a conformação de produtos experienciais para consumidores que se enquadram na categoria dimensional de evasão de Pine e Gilmore (1999) realizou-se uma pesquisa bibliográfica, exploratória e descritiva sobre a economia da experiência, com o intuito de criar familiaridade com o tema mediante a descrição de características deste fenômeno, devido à necessidade crescente do manuseio de novos aspectos experienciais para o desenvolvimento de produtos e serviços para consequentemente agregar valor à viagem ou passeio (Mehmetoglu e Englen, 2011, Creswell 2007).

A pesquisa de múltiplos métodos, consiste na combinação entre método qualitativo e método quantitativo, de forma a proporcionar um maior entendimento em relação a temática da investigação (Creswell, 2007). Em primeiro momento foi utilizado a abordagem quantitativa, definida por Creswell (2007) como uma pesquisa de levantamento de dados numéricos.

A coleta de dados foi realizada através da plataforma interativa do sítio eletrônico TripAdvisor, na qual definiu um corte transversal sob critérios definidos previamente com o intuito de delimitar uma amostra concisa do estado do Paraná. Em seguida foi executada uma 
observação qualitativa dos comentários vinculados aos atrativos, como forma de extração de informações que ampliasse a compreensão do objeto de pesquisa (Almeida e Sá-Silva, 2009).

Para dados retirados da internet, especificamente do Tripadvisor, utilizou-se a netnografia, que possibilita estudar o comportamento do consumidor em comunidades (redes) virtuais (Kozinets, 1998; Pereira, 2005). O tripadvisor conta com o compartilhamento das experiências de seus usuários de forma pública, por meio de comentários, avaliações e fotografias, oportunizando o uso dessas informações para fins de pesquisa.

O produto turístico resulta na soma de elementos para sua oferta, sendo esses atrativos e facilidades caracterizadas pela presença de alojamento, alimentação e transporte que somado com a imagem do destino é vendido por determinado preço (Middleton E Clarke ,2002). Logo foram observadas as três variáveis que caracterizam o município como produto, sendo atrativos, acomodações e restaurantes.

1. Foram selecionados municípios em que a quantidade de avaliações fosse superior ou igual a 2000. Houve a somatória das seguintes variáveis: atrações, acomodações e restaurantes.

2. Foram selecionados aqueles atrativos que obtiveram mais de 92 avaliações para compor um produto-roteiro.

Desta forma, foram elencados municípios e atrativos para as características do segmento referente à demanda por natureza e por cultura, de forma a viabilizar uma análise de produtos experienciais para consumidores que se encaixe na dimensão evasão. Neste trabalho, os atrativos foram classificados como aposta, prioritário ou consolidado conforme observações específicas:

- Consolidado - Atrativo com alta avaliação no Tripadvisor ou alta relevância para o turismo local;

- Prioritário - Atrativo que não atingiu altas avaliações, mas com o passar do tempo há chances para que este se popularize e consolide;

- Aposta - Atrativo que possui baixa avaliação ou ainda é um atrativo novo no mercado turístico.

No Plano Paraná Turístico 2026 consta um levantamento de 37 empresas de receptivos no estado que comercializam pacotes turísticos formados a partir de informações da internet e plataformas com conteúdo relacionado a turismo. Nota-se que os principais atrativos que constam no Tripadvisor são os mesmos que compõe os pacotes comercializados por estas empresas.

\section{ANÁLISE DE RESULTADOS E IMPLICAÇÕES}

Segundo Lugosi e Walls (2013), a experiência de consumo precisa estimular múltiplos sentidos e emoções através da interação de diferentes processos e atores com o intuito de ampliar a experiência do cliente, para tanto, compreender o ambiente em que se desenvolve a atividade do turismo, bem como a demanda pelo município e atrativo, torna-se essencial. 
Como instrumento deste entendimento foi utilizado à classificação dimensional que compõe a evasão, proposta por Pine e Gilmore (1999).

A dimensão evasão consiste na interação de forma ativa, consumindo o produto ao mesmo tempo em que este é produzido pelos gestores do destino. Consequentemente, há a possibilidade de influenciar a experiência do cliente com o manuseio de diferentes elementos do destino (Mehmetoglu e Englen, 2011, Paraná 2016, Lugosi e Wall, 2011).

O perfil do consumidor demandante por produtos da dimensão de evasão, de Pine e Gilmore (1999), anseia por sentir-se membro da comunidade na qual está conhecendo, mediante a essa característica a interação e relacionamento ocorrem de forma ativa com a comunidade (Paraná, 2016). Visto isso, a participação ativa do turista exige dos gestores a habilidade em combinar elementos exatos para a percepção cognitiva do participante quanto ao ambiente (Mondo e Gândara, 2017).

O Plano Paraná Turístico 2026 propõe a descrição da persona buscadora de experiências de natureza e cultura, como já abordada anteriormente, através do design thinking, esse projeta produtos considerando diferentes comportamentos e características, fato do qual viabiliza a segmentação para o destino Paraná (Horodyski, 2014, Paraná 2016).

Nota-se que alguns municípios do estado do Paraná-BR possuem atrativos tanto de natureza quanto cultural, atendendo desta forma duas demandas que se correlacionam através da dimensão evasão e que podem vir a ser atrativos complementares, a llha do Mel, por exemplo, tem como atrativo cultural o Farol das conchas e a Gruta das Encantadas como atrativo natureza e assim como ela, os municípios de Paranaguá, Curitiba, Lapa, Cascavel, Foz do Iguaçu e Londrina.

\subsection{Buscadores de experiência de natureza}

A persona que busca por experiências de natureza possui como característica a motivação por atividades de aventura e ecoturismo, procuram por bons passeios para usufruir das belezas naturais, visitam os atrativos do destino em uma programação independente optando por caminhadas, trilhas e cicloturismo. Geralmente o consumidor possui conhecimento do local, sendo em alguns casos uma segunda visita com a família (Paraná, 2016).

Segundo Lugosi e Walls (2013) a experiência tem uma dimensão espacial significativa a partir do envolvimento dos consumidores com espaços em contexto de escape, familiaridade e segurança, no qual os lugares também são pontos de lembranças.

A tabela 01 se refere à amostragem resultante da coleta de dados, bem como sua notória correspondência à persona natureza. Totalizam 36 atrativos que podem atender a demanda por experiências de natureza mediante a trilha, caminhadas e passeios ecológicos em meio à flora e fauna do estado com cachoeiras, parques, reservas ambientais que fomentam o ecoturismo.

A experiência é construída no momento em que o consumo do turismo e a produção se encontram, essa dinâmica acontece quando as necessidades básicas, sociais e intelectuais são atingidas ocasionando aumento do nível de excitação (Anderson, 2007). A acessibilidade 
e serviços básicos de visitação são os primeiros elementos que influenciam na experiência em relação ao local. Após atender as primeiras necessidades o consumidor estará pronto para consumir novos produtos que, segundo Anderson (2007) será manuseado através dos recursos genéticos oriundos da relação tempo, habilidade, bens e serviços.

Ao observar a avaliação de alguns atrativos, retirados da plataforma do TripAdvisor, descritos abaixo, é possível notar aspectos do consumo em relação ao local. Nota-se nos comentários o relato da experiência atrelada à descrição da estrutura e acessibilidade ao local, confirmando a perspectiva de Anderson (2007), estes constituem elementos básicos da oferta.

Atrativo: Parque Ilha do Mel.

"Um pedaço do paraíso no Paraná!! Amamos cada minuto! Um lugar lindo, calmo, longe da correria do dia a dia, para você ir de mochila e se jogar!! Andar de chinelo e biquíni o dia inteiro, apreciar o reflexo da lua e do plâncton bioluminescente no mar!! Vale suuuuper a pena!! Melhor caminho para chegar é ir por Pontal do Sul e não por Paranaguá: menos trânsito e menor tempo de travessia. Escolhendo uma boa pousada, você tem toda a comodidade da cidade grande (Wi-Fi, ducha quente, ar condicionado). Recomendo ficar na Praia de Encantadas, se você gosta de vida noturna e sair para comer a noite. O deslocamento pela ilha da para ser feito de barco ou lancha, em vários horários do dia!" (Tripadvisior, 2016)²

Tabela 1. Dimensão Evasão - persona natureza - atrativos turísticos segundo mercado e principais municípios

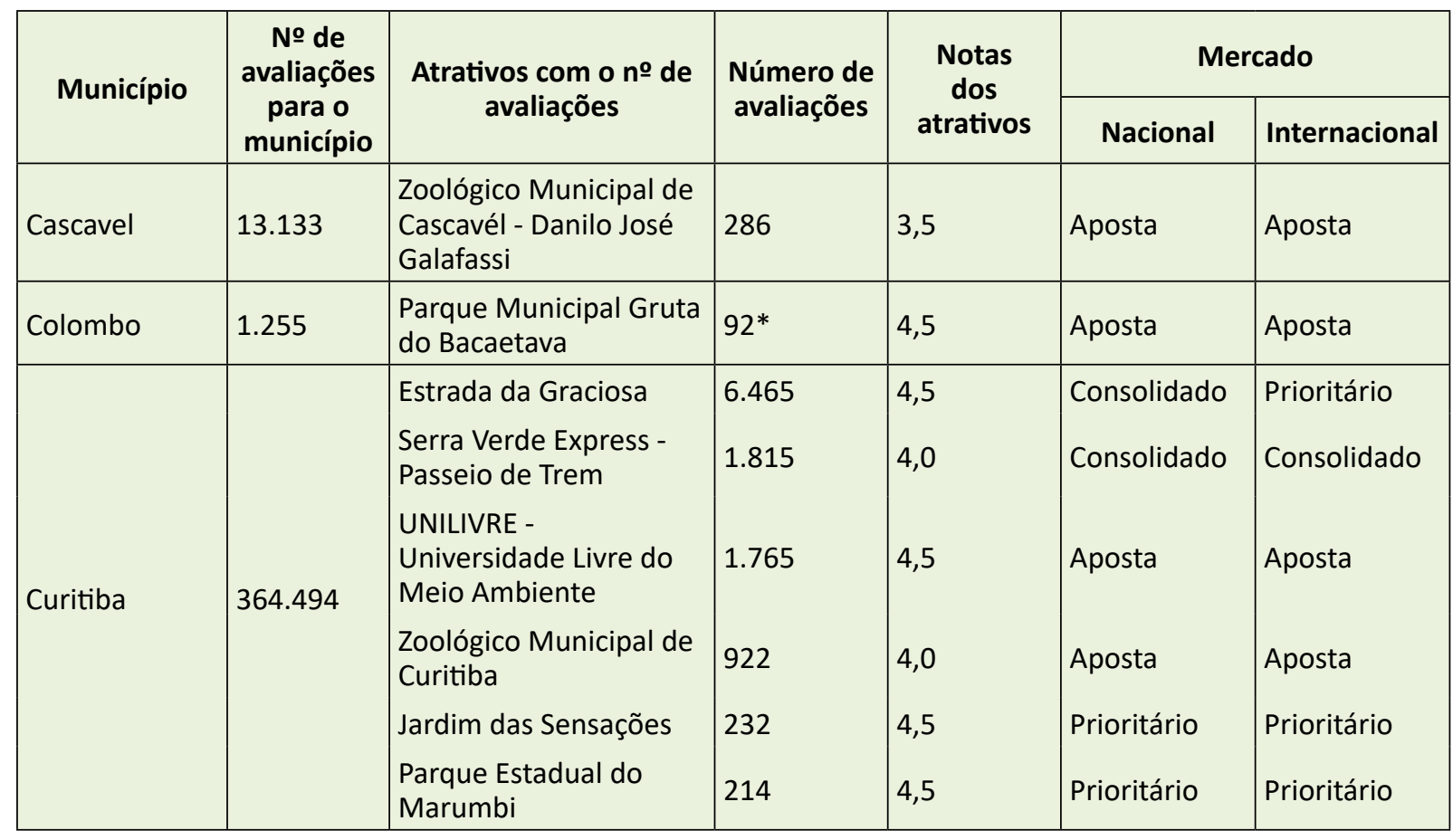

2. Avaliação Realizada em 06/02/2018. Disponível em goo.gl/4tXynK. 


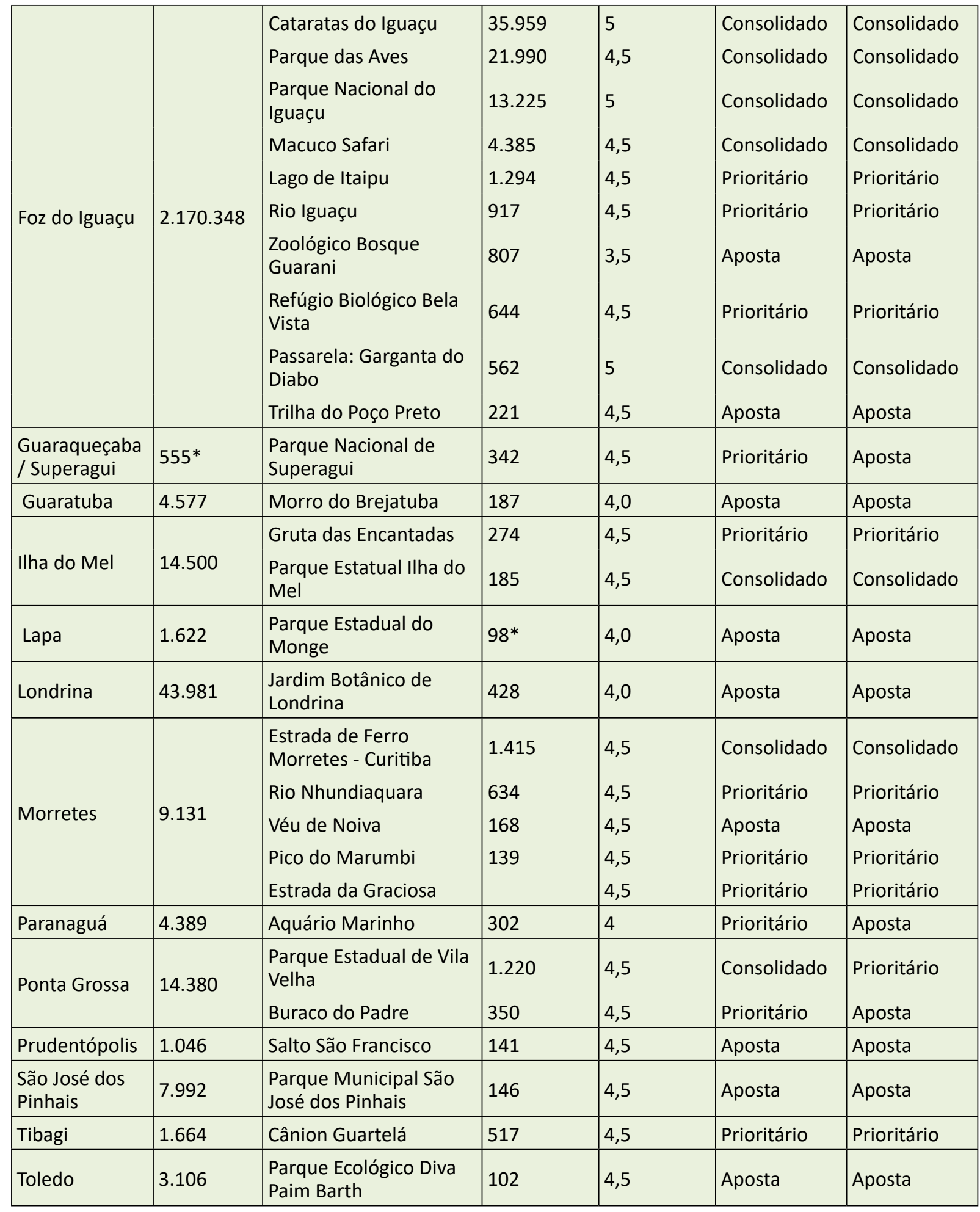

Fonte: Autores

Atrativo: Estrada da Graciosa:

"O caminho é melhor que a chegada "A Estrada da Graciosa" é um evento a parte. Cada curva é uma nova descoberta. Estrada muito charmosa e agradável de passear. A cada momento da viagem você se 
depara com uma paisagem ou atração diferente. A natureza em torno da estrada é muito bonita. Há diversos pontos de parada com mirantes, rios, cachoeiras, alguns bares/restaurantes. Sinceramente, gostei muito mais da viagem pela Estrada da Graciosa do que propriamente da visita a Morretes e Antonina. Único ponto negativo é que por ser uma estrada antiga, ela é bastante sinuosa e estreita, com pouca iluminação, além de ter uma parte em paralelepípedo. Assim sendo, não recomendo o trânsito à noite."(Tripadvisior) ${ }^{3}$

Atrativo: Parque Estatual Vila Velha:

Maravilhoso. Superou muito minha expectativa! Lindo!! Organizado, com ônibus, guias especializados, loja, lanchonete, banheiros. A Trilha, os formatos, a lenda, a explicação científica, vegetação, animais na trilha, maravilhoso! (Tripadvisior, 2016) ${ }^{4}$

Na figura 5, é possível visualizar geograficamente os municípios que se referem à natureza, estes se concentram na região Oeste do estado Foz do Iguaçu, Cascavel e Toledo, no centro oriental Prudentópolis, Tibagi e Ponta Grossa, na região metropolitana Curitiba, São José dos Pinhas, Morretes, Guaraqueçaba, Guaratuba, Paranaguá, Ilha do $\mathrm{Mel}^{5}$ e Colombo, ao norte central encontra-se Londrina e Lapa na região sudeste.

Figura 05. Buscadores de experiência de natureza

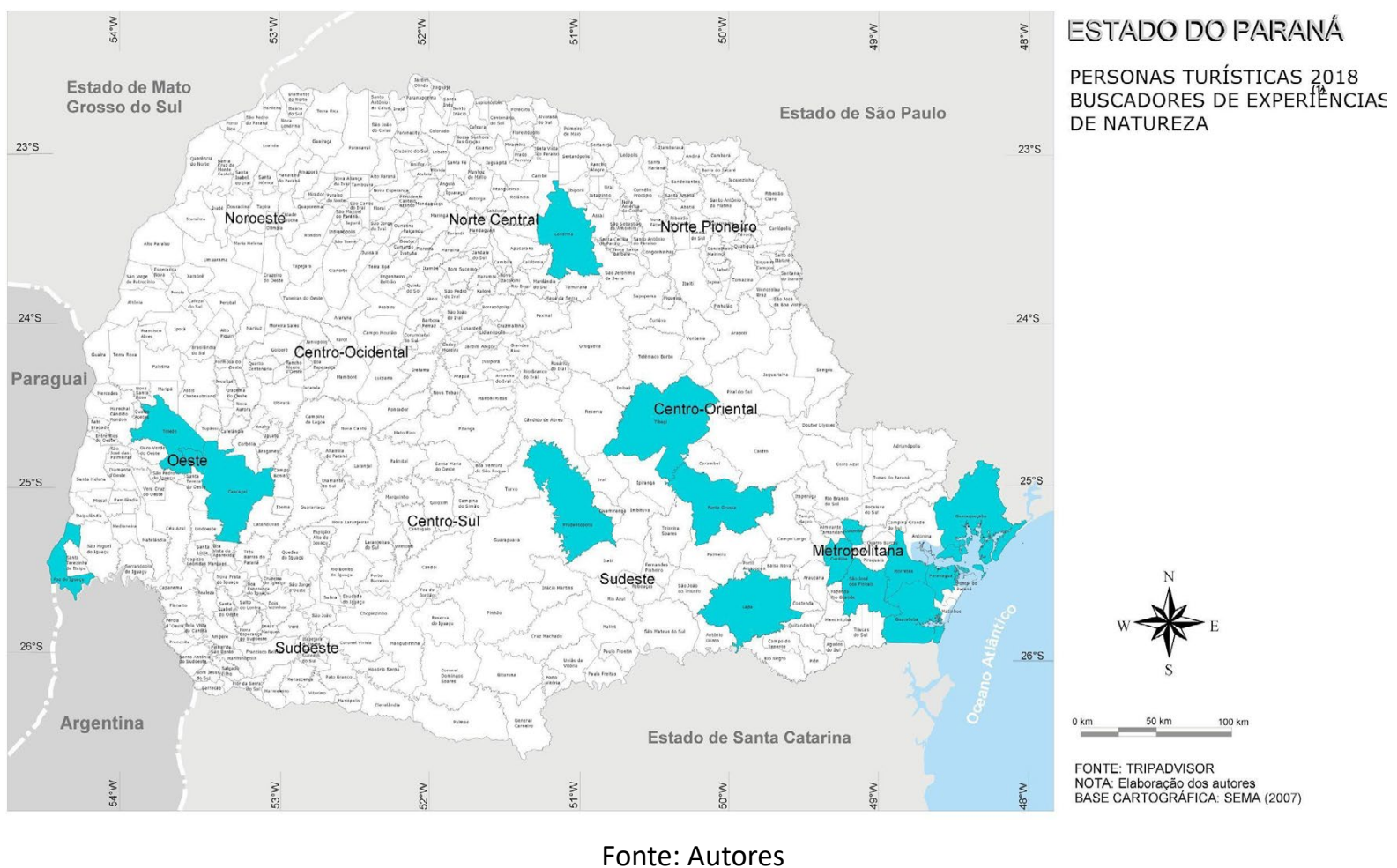

3. Avaliação Realizada em 08/02/2018. Disponível em goo.gl/ci7h5P.

4. Avaliação Realizada em 01/02/2018. Disponível em goo.gl/5au7wX.

5. A llha do Mel é distrito do município de Paranaguá, mas durante o levantamento de dados na plataforma da TripAdvisor este deste destino turístico não apresentava vínculo com o município do qual pertence. 
Para turistas que buscam por experiências na natureza, com a característica ativa e dinâmica, podem-se conformar produtos que constituem um processo de experiência extraordinária. Esse pode ser trabalhado através da integração de componentes de interação e significado no destino, promovendo sensações de alegria e satisfação associada a algo novo durante o passeio. As experiências significativas ocorrem quando somadas a interações com o meio ambiente durante todo o processo de conhecimento do local (Mehmetoglu e Engen, 2011).

Os turistas procuram experiências autênticas e podem participar de uma variedade de experiências de consumo (Lugosi e Walls 2013). Explorar o consumo através da co-criação, oriunda dos envolvimentos em várias situações delineadas pelos gestores, é uma forma de agregar valor à experiência final de forma ativa (Prebensen e Foss, 2003).

Segundo Ek et al (2008) a conformação de produtos para natureza pode ser realizada pela exploração não controlada da experiência, mediante ao redesenho constante da sensação emocional pelo turista sob um contexto de desing de experiência por parte do gestor.

\subsection{Buscadores de experiência de cultura}

A persona referente à cultura tem como principal motivação a busca por conhecer as características culturais do destino, bem como o envolvimento com a história e gastronomia local, portanto são adeptos a períodos longos de estadia para vivenciar o destino (Paraná 2016). Este consumidor valoriza o estilo de viagem "SlowTourism", que possui como característica a integração ao destino com maior contato com a população e cultura local, para este consumidor o tempo é considerado o aspecto precioso na viagem de forma desacelerar o consumo (Mateo, 2013, Paraná, 2016).

A tabela 02 apresenta os municípios correspondentes à persona cultura, esses totalizam 47 atrativos culturais concentrados em um número menor de municípios, atendendo a demanda que possui interesse em adquirir conhecimento em relação à história e cultura local com museus, teatros e memoriais.

Tabela 2. Dimensão Evasão - persona cultura - atrativos turísticos segundo mercado e principais municípios.

\begin{tabular}{|c|c|c|c|c|c|c|}
\hline \multirow[b]{2}{*}{ Município } & \multirow{2}{*}{$\begin{array}{c}\text { № de } \\
\text { avaliações } \\
\text { para o } \\
\text { município }\end{array}$} & \multirow[b]{2}{*}{ Atrativos com o no de avaliações } & \multirow[b]{2}{*}{$\begin{array}{l}\text { Número de } \\
\text { avaliações }\end{array}$} & \multirow{2}{*}{$\begin{array}{c}\text { Notas } \\
\text { dos } \\
\text { atrativos }\end{array}$} & \multicolumn{2}{|c|}{ Mercado } \\
\hline & & & & & Nacional & Internacional \\
\hline \multirow{2}{*}{ Antonina } & \multirow{2}{*}{2.070} & Setor Histórico & 115 & 4 & Prioritário & Aposta \\
\hline & & Ruínas do Casarão Macedo & 99 & 3,5 & Aposta & Aposta \\
\hline Carambeí & 2.212 & Parque Histórico de Carambeí & 374 & 4,5 & Prioritário & Prioritário \\
\hline \multirow[b]{2}{*}{ Cascavel } & \multirow[b]{2}{*}{13.133} & Teatro Municipal de Cascavel & 159 & 4,5 & Aposta & Aposta \\
\hline & & $\begin{array}{c}\text { Praça do Migrante - Florêncio } \\
\text { Galafassi }\end{array}$ & 115 & 4,0 & Aposta & Aposta \\
\hline Castro & 2.236 & Centro Cultural Castrolanda & 178 & 4,5 & Prioritário & Prioritário \\
\hline
\end{tabular}




\begin{tabular}{|c|c|c|c|c|c|c|}
\hline \multirow{24}{*}{ Curitiba } & \multirow{24}{*}{364.494} & Museu Oscar Niemeyer & 11.563 & 4,5 & Consolidado & Consolidado \\
\hline & & $\begin{array}{c}\text { Bosque do Papa \& Memorial da } \\
\text { Imigração Polonesa }\end{array}$ & 2.312 & 4,5 & Consolidado & Consolidado \\
\hline & & $\begin{array}{c}\text { Memorial da Imigração } \\
\text { Ucraniana }\end{array}$ & 2.079 & 4,5 & Prioritário & Prioritário \\
\hline & & Centro Histórico de Curitiba & 1.889 & 4,5 & Consolidado & Prioritário \\
\hline & & $\begin{array}{l}\text { Praça do Japão + Memorial da } \\
\text { Imigração Japonesa }\end{array}$ & 1.448 & 4 & Consolidado & Prioritário \\
\hline & & Universidade Federal do Paraná & 1.357 & 4,5 & Prioritário & Prioritário \\
\hline & & Teatro HSBC - Palácio Avenida & 1.348 & 4,5 & Consolidado & Consolidado \\
\hline & & Museu do Holocausto de Curitiba & 1.068 & 4,5 & Prioritário & Prioritário \\
\hline & & SESC Paço da Liberdade & 802 & 4,5 & Prioritário & Prioritário \\
\hline & & Memorial de Curitiba & 715 & 4 & Prioritário & Prioritário \\
\hline & & Museu Ferroviário & 570 & 4 & Aposta & Aposta \\
\hline & & Museu Egipcio Ordem Rosacruz & 493 & 4,5 & Aposta & Aposta \\
\hline & & $\begin{array}{l}\text { Memorial da Segurança no } \\
\text { Transporte }\end{array}$ & 416 & 5 & Aposta & Aposta \\
\hline & & Museu do Automóvel & 379 & 4 & Aposta & Aposta \\
\hline & & Museu Paranaense & 322 & 4,5 & Prioritário & Prioritário \\
\hline & & Pedreira Paulo Leminski & 313 & 4,5 & Prioritário & Prioritário \\
\hline & & Museu do Expedicionário & 298 & 4,5 & Aposta & Aposta \\
\hline & & Teatro Lala Schineider & 255 & 4,5 & Aposta & Aposta \\
\hline & & $\begin{array}{l}\text { Museu da Arte Sacra da } \\
\text { Arquidioceses de Curitiba }\end{array}$ & 196 & 4 & Prioritário & Prioritário \\
\hline & & Biblioteca do Paraná & 164 & 4,5 & Aposta & Aposta \\
\hline & & Teatro Paiol & 149 & 3,5 & Aposta & Aposta \\
\hline & & Memorial de Curitiba & 140 & 4 & Prioritário & Prioritário \\
\hline & & Memorial Árabe & 114 & 3,5 & Aposta & Aposta \\
\hline & & Centro Cívico de Curitiba & 96 & 4 & Prioritário & Prioritário \\
\hline \multirow{5}{*}{ Foz do Iguaçu } & \multirow{5}{*}{270.348} & Usina Hidrelétrica de Itaipu & 16.928 & 4,5 & Consolidado & Consolidado \\
\hline & & Museu de Cera Dreamland & 3.043 & 3,5 & Consolidado & Prioritário \\
\hline & & Marco das três Fronteiras & 2.749 & 4,5 & Consolidado & Consolidado \\
\hline & & Ecomuseu de Itaipú & 1.055 & 4 & Prioritário & Prioritário \\
\hline & & $\begin{array}{l}\text { Polo Astronômico Casimiro } \\
\text { Montenegro Filho }\end{array}$ & 438 & 4,5 & Prioritário & Prioritário \\
\hline \multirow{5}{*}{ Lapa } & \multirow{5}{*}{1.622} & Theatro São João & 125 & 4,5 & Aposta & Aposta \\
\hline & & Museu das Armas & 116 & 4,5 & Prioritário & Prioritário \\
\hline & & Casa Cel. Joaquim Lacerda & 115 & 4,5 & Prioritário & Prioritário \\
\hline & & Museu Histórico da Lapa & 99* & 4 & Aposta & Aposta \\
\hline & & Panteom dos Heróis & $91^{*}$ & 4 & Aposta & Aposta \\
\hline \multirow{3}{*}{ Londrina } & \multirow{3}{*}{43.961} & $\begin{array}{l}\text { Museu Histórico de Londrina } \\
\text { "Padre Carlos Weiss" }\end{array}$ & 290 & 4,5 & Prioritário & Aposta \\
\hline & & Teatro Marista & 157 & 4,5 & Prioritário & Aposta \\
\hline & & Biblioteca Municipal & 114 & 4 & Aposta & Aposta \\
\hline Maringá & 27.957 & Teatro Calil Haddad & 135 & 4,5 & Prioritário & Prioritário \\
\hline Paranaguá & 4.389 & $\begin{array}{l}\text { Museu de Arqueologia e } \\
\text { Etnologia da Universidade } \\
\text { Federal do Paraná }\end{array}$ & 146 & 4,5 & Prioritário & Prioritário \\
\hline \multirow[b]{2}{*}{ Ilha do Mel } & \multirow[b]{2}{*}{10.849} & Farol das Conchas & 196 & 4,5 & Prioritário & Prioritário \\
\hline & & $\begin{array}{c}\text { Fortaleza Nossa Senhora dos } \\
\text { Prazeres }\end{array}$ & 156 & 4,5 & Prioritário & Prioritário \\
\hline
\end{tabular}

Fonte: Autores 
A decisão por viajar é influenciada por fatores de pressão, essas tangenciam suas necessidades e desejos, e por fatores de atração que embasam as características dos atributos do destino, suas instalações e acessibilidade. Os fatores de pressão precedem os fatores de atração, o que torna a experiência essencial para a satisfação e fidelização do cliente (PulidoFernández, Navarro, 2014). Abaixo constam alguns relatos de experiência que surpreenderam as expectativas atendendo aos dois aspectos da decisão de viajar.

Atrativo: Centro Histórico de Curitiba:

"Fomos lá num Domingo. Dia que tem uma feirinha, com tudo que se possa imaginar. Roupas, artesanato, comidas, antiguidades. A feira é muito grande. Ainda vimos uma exposição de carros antigos. E no final, fomos presenteados com a visita a belíssima Mesquita Azul. Vale a visita. Tem que se tirar os sapatos ao entrar, e as mulheres precisam colocar um lenço na cabeça" (Tripadvisor,2016)

Atrativo: Museu Histórico de Londrina "Padre Carlos Weiss"

"Emocionante. VOCÊ VAI conseguir TER uma ÓTIMA noção da história de Londrina e das terras vermelhas do Norte do Paraná passeando neste belo museu. Encontram-se nele fotos belíssimas que nos levam para aqueles tempos, em que os ingleses vieram desbravar a região. IMPERDÍVEL!!!!". (Tripadvisor, 2016) ${ }^{7}$

\section{Atrativo: Polo Astronômico Casimiro Montenegro Filho}

"Pensar o espaço é mágico. Um lugar onde se pode aprender sobre o infinito, buscar compreender mistérios e se instigar com a grandeza de universo que ainda nem foi totalmente descoberto (e nem será). Monitores muito bem capacitados! Se der a sorte de ir num dia de céu aberto, o passeio estará mais do que completo!"(Tripadvisor, 2016) ${ }^{8}$

Além dos atrativos presentes na tabela 02, vale ressaltar alguns eventos que também são atrativos turísticos. Dentre os mais conhecidos de cunho cultural estão o Festival de Teatro e o Natal do HSBC em Curitiba e o Festival de Inverno em Antonina. E ainda, pelo viés gastronômicos, ocorre a Festa nacional do Carneiro no Buraco em Campo Mourão e na cidade de Toledo Festivais que usam o prato típico Porco no Rolete.

Os eventos citados podem complementar o turismo nas referidas cidades, uma vez que o consumidor do turismo não compra apenas uma viagem, mas uma experiência, no qual o produto é um conjunto de vários componentes que podem ser criados, alterados ou arranjados de diversas formas conforme a identificação das necessidades dos turistas e visando suas expectativas (Middleton e Clarke, 2002).

Os consumidores que buscam experiências de cultura possuem a experiência diretamente atrelada ao impacto emocional. Estas emoções são estados afetivos caracterizados por episódios de sentimentos intensos associados a um referente específico, de forma que o gestor

6. Avaliação Realizada em 04/02/2018. Disponível https://goo.gl/U8bHW9.

7. Avaliação realizada em 18/11/2017. Disponível https://goo.gl/GEyMcz.

8. Avaliação realizada em 05/02/2017. Disponível https://goo.gl/xtXECR. 
da experiência instigue comportamentos de resposta específicos. Os estados de espírito são estados de sentimento transitórios e penetrantes que ocorrem em situações específicas ou em momentos específicos. O turista não compra um produto, ele compra emoções (Middleton e Clarke 2002; Gardner 1985, Cohen e Areni, 1991 aphud Hosany e Prayag 2013).

A figura 6 demonstra geograficamente onde se concentra os atrativos para os buscadores de experiência de cultura. Os municípios com atributos culturais encontram agrupados nas regiões do Oeste com Foz do Iguaçu e Cascavel, no norte oriental com Carambeí e Castro, região metropolitana Antonina, Curitiba, Paranaguá e Ilha do Mel, norte central Londrina e Maringá e Lapa no sudeste.

Nota-se gestão de experiência precisa considerar a interação, planejamento, personalidade, design e ambiência, integração da prestação de serviço com abordagens diferentes e estratégicas para criar valor, e de forma inovadora explorar recursos através da criatividade e distinção cultural, com o intuito de trabalhar positivamente um destino turístico conforme suas características próprias de localização e atrativos (Morgan, Elber, Curriel, 2011).

Figura 6. Buscadores de experiência de cultura.

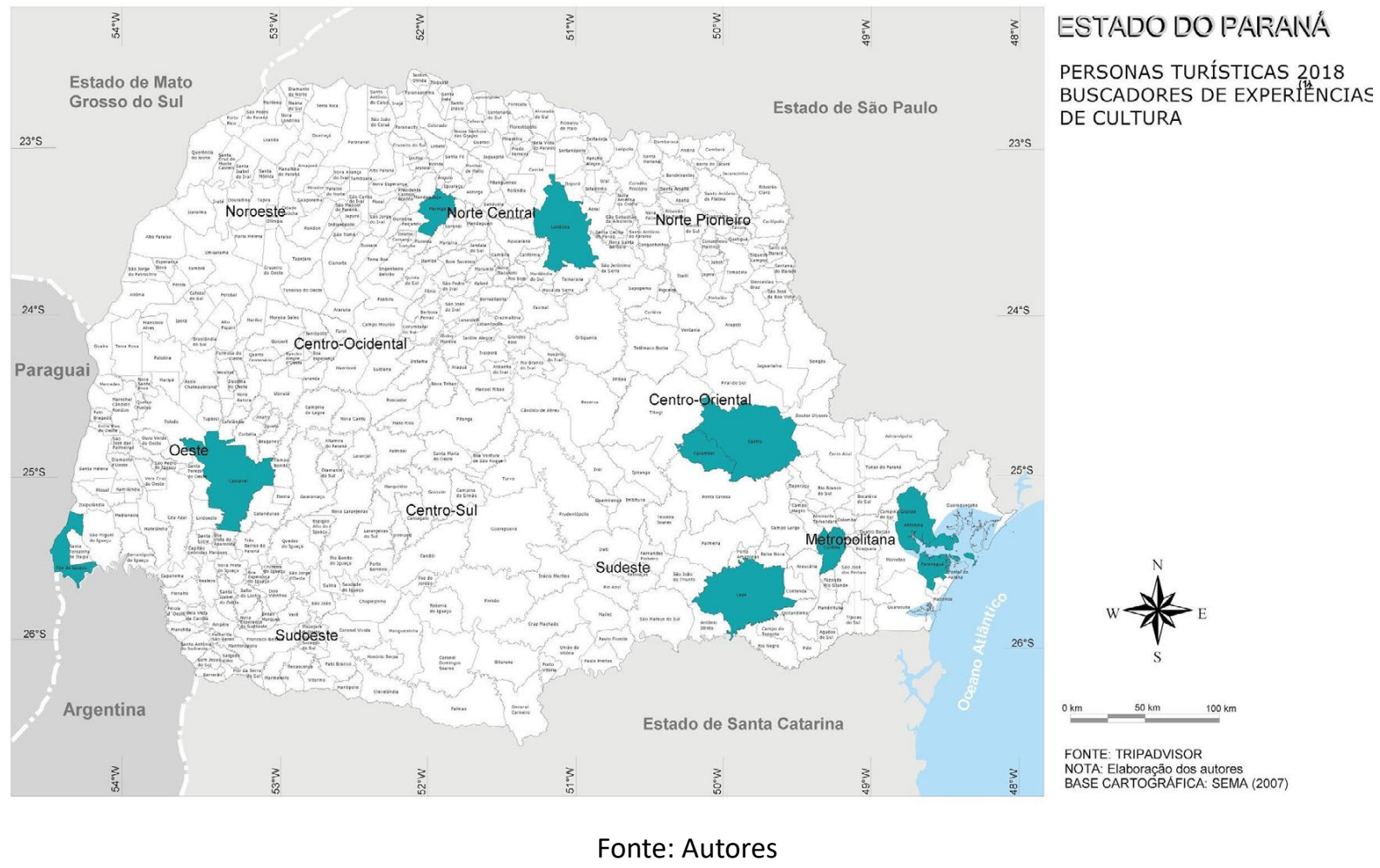

Para Marujo (2016) a natureza da experiência turística é multidimensional e sensorial, essa é a ideia principal para se compreender o âmbito experiencial do turismo e viabiliza-lo de forma propor produtos experienciais. A criatividade é uma via interessante para conformar produtos experiências para consumidores de elementos culturais, através da imaginação e estímulos sensoriais a partir da promoção de eventos e atividades que despertem emoção, envolvimento e interação do turista. Os autores Richards e Wilson (2006) propõe a reorientação 
de modelos do turismo cultural mediante a criatividade, através de estratégias que (re)valorizem o lugar, criam de narrativas no espaço, promovem atividades criativas e inovadoras.

\section{CONSIDERAÇÕES FINAIS}

O modelo dimensional de experiências de consumo proposta por Pine e Gilmore (1999), se mostrou um caminho interessante para ser explorado dentro do planejamento e organização do turismo, uma vez que propõem a identificação das características da oferta do destino e a demanda de consumo.

Além da procura de produtos e serviços com qualidade, os atuais consumidores buscam por experiências únicas, consumidores pagam por experiências sensoriais e intangíveis, no qual o valor está altamente ligado vivencia de momentos permeiam um momento memorável ao se realizar uma atividade (Pine E Gilmore 1999, Richards 2001, Pulido-Fernández, Navarro, 2014).

O Plano Paraná Turístico - Pacto para um destino inteligente se mostra efetivo no que se refere a ações metodológicas para desenvolver a atividade turística mediante ao aporte da economia da experiência e construção de perfis de demanda com a técnica de "personas" do "design thinking. A aplicabilidade das dimensões de Pine e Gilmore (1999) se mostrou viável para gerenciar o turismo sob a via mercadológica com o desenvolvimento produtos para diferentes demandas.

No que se refere à dimensão de evasão, foco do trabalho, o aumento da interação entre o turista e o destino, através da co-criação, pode-se potencializar a imersão ativa na experiência propondo absorção de conhecimento e transformação com uma gestão de temas inovadores, criatividade e autenticidade (Gelter, 2010). Na dimensão evasão o consumo é ativo, portanto os gestores precisam ter habilidades para manusear experiências que dependam da participação deste turista, pois a persona da natureza e cultura irá produzir a experiência no mesmo momento do consumo do produto (Mehmetoglu e Engen, 2011).

Por fim, a investigação dos municípios do Paraná permite o conhecimento da distribuição dos atrativos turísticos, bem como a reputação dos destinos que pode ser trabalhada através a segmentação e a conformação de produtos com aporte da segmentação da demanda interligada com perfis de consumidores e apoio dos conceitos da economia da experiência.

\section{REFERÊNCIAS}

Amadeus (2015). Future Traveller Tribes 2030: Understanding Tomorrow's Traveller.Revista Amadeus. p 1-70.DOI https://goo.gl/s9nDFe.

Andersson, T.D (2007). The tourist in the experience economy. Scandinavian journal of hospitality and tourism, 7 (1), p. 46-58.

Buhalis, D. (2000). Marketing the competitive destination of the future. Tourism management, v. 21 , n. 1, p. 97-116.

Binkhorst, E. (2017). Turismo de co-creación, valor añadido en escenarios turísticos. ARA: Revista de Investigación en Turismo, 1 (1). 
Creswell, J. W. (2007). Uma estrutura para projeto. Projeto de pesquisa: métodos qualitativo, quantitativo e misto. Porto Alegre: Artmed, 21-42.

EK, R., Larsen, J., Hornskov, S. B., \& Mansfeldt, O. K. (2008). A dynamic framework of tourist experiences: Space-time and performances in the experience economy. Scandinavian Journal of Hospitality and Tourism, 8(2), 122-140.

Ejarque, J. (2005). destinos Turísticos de Éxito-Diseño. Creación, Gestión y Marketing. Madrid, Ediciones Pirámide.

Framke, W. (2002). The destination as a concept: A discussion of the business-related perspective versus the socio-cultural approach in tourism theory. Scandinavian Journal of Hospitality and Tourism, 2 (2), p. 92-108.

Flores, L. C. ;Mendes, J. (2014). Perspectivas do destino turístico: repensando o sentido do conceito. Revista Brasileira de Pesquisa em Turismo, 8(2), p. 222-237.

Gelter, Hans (2010) Total Experience Management: a conceptualmodel fortransformationalexperiences within tourism. In: Nordic conference on experience 26/11/2008-28/11/2008. Tritonia, p. 46-78.

Jovicic, Dobrica Zivadin. Key issues in the conceptualization of tourism destinations. Tourism Geographies, v. 18, n. 4, p. 445-457, 2016.

Lugosi, P.; Walls, A. R. (2013) Researching destination experiences: Themes, perspectives and challenges. Journal of Destination Marketing and Management, 2 (2), p. 51-58.

Lundy, L. (2018) Future Traveller Tribes 2030: Building a more rewarding journey. [s.l.]: Frost \& Sullivan, 2015. Disponível em: Amadeus.com/tribes2030.

Ejarque, J. (2005). Destinos Turísticos de Éxito-Diseño. Creación, Gestión y Marketing. Madrid, Ediciones Pirámide..

Marujo, N. (2016). Turismo, turistas e experiências: Abordagens teóricas. Revista TURyDES Turismo y Desarrollo Local, 9(20), 1-13.

Mateos, M. R. (2013). El turismo experiencial como forma de turismo responsable e intercultural. In Relaciones interculturales en la diversidad (pp. 199-217). Cátedra Intercultural.

Mehmetoglu, M.; Engen, M. (2011) Pine and Gilmore's concept of experience economy and its dimensions: An empirical examination in tourism. Journal of Quality Assurance in Hospitality \& Tourism, 12(4) p. 237-255.

Middleton, V. T., \& Clarke, J. (2002). Marketing de Turismo: teoria \& prática. Elsevier.

Morgan, M., Elbe, J., \& de Esteban Curiel, J. (2009). Has the experience economy arrived? The views of destination managers in three visitor-dependent areas. International Journal of Tourism Research, 11(2), 201-216.

Neuhofer, B.; Buhalis, D.; Ladkin, A. (2012) Conceptualising technology enhanced destination experiences. Journal of Destination Marketing \& Management, 11 (2), p. 36-46.

Paraná (2016). Governo do Estado do Paraná. Secretaria de Esporte e turismo (Org). Paraná Turístico 2016: Pacto para um destino inteligente. Disponível em: <goo.gl/y8Xi9z>. Acesso em: Novembro 2017.

Paraná. (2018). Governo do Estado do Paraná. Secretaria de Esporte e turismo (Org). Paraná Turístico 2016: Plano Estratégico de Marketing para um destino inteligente. P.70.

Petrocchl, M. Turismo: Planejamento e Gestão. São Paulo: Pearson Prentice Hall, 2009. Turismo: Planejamento e Gestão de Polos turísticos. São Paulo: Futura, 2001. 
Prebensen, N. K.; Foss, L. (2011) Coping and co-creating in tourist experiences. International Journal of Tourism Research, 13 (1), p. 54-67.

Pine, B. J., Pine, J., \& Gilmore, J. H. (1999). The experience economy: work is theatre \& every business a stage. Harvard Business Press.

Prahalad, C. K.; Ramaswamy, V. (2004) Co-creation experiences: The next practice in value creation, Journal of Interactive Marketing, 18 (3), p. 5-14.

Pulido-fernández, J. I.; Hermoso, Ú. N. (2015) Identificación de ítems para medir las experiencias del turista en destino. CULTUR-Revista de Cultura e Turismo, 8 (1), p. 04-34.

Prahalad, C. K.; Ramaswamy, V. (2003) The new frontier of experience innovation. MIT Sloan management review, 44 (4) p. 12-18.

Richards, G., \& Wilson, J. (2006). Developing creativity in tourist experiences: A solution to the serial reproduction of culture? Tourism management, 27(6), p. 1209-1223.

Timón, D. (2004) El concepto de destino turístico. Una aproximación geográfico-territorial. Estudios turísticos, 160, p. 45-68.

Thomaz, G. M. (2016). Personas/Perfis da demanda turística para o Paraná em 2026. Curitiba: Fecomercio-PR, 8 (9). 